\title{
METODS OF CALCULATION OF OPTIMAL PARAMETERS OF ROLLING
}

\author{
I. Stadnyk, S. Fedak \\ Ternopil Ivan Pului National Technical University \\ B. Pashchenko, N. Tkachuk \\ National University of Food Technologies
}

\begin{tabular}{l} 
Key words: \\
Dough \\
Injection \\
Heat conduction \\
Heat propagation \\
Heat flux \\
Roll \\
Phase \\
Medium \\
\hline
\end{tabular}

Article history:

Received 08.11.2018

Received in revised form

29.11.2018

Accepted 13.12.2018

Corresponding author:

I. Stadnyk

E-mail:

npnuht@ukr.net

\section{ABSTRACT}

The analytical analysis of roller impact on the medium and its behavior at deformation influences are carried out, ways of choosing an optimal variant of the process for providing the maximum or minimum value of parameters (criterion) are proposed. The physical essence of the equation of energy flows of the intensity of deformation of the mass of the medium, which depends on the method of applying mechanical forces, the degree of its previous dispersion (recipe) and its physical and mechanical properties, is considered. For a more visual view and understanding of the overall performance of the research, a scheme of causal relationships between the medium and the roll, which determine the temperature change of the dough injection process, is proposed.

It is noted that the definition of temperature fluxes during the process of injection of the medium by roller working bodies plays an important role in calculating the design of molding, roll-over, mixing equipment. The obtained data answer a number of questions about the possibility of thermoregulation of the process of the work of the working bodies into the environment. A set of measures for measuring the temperature during the use of devices was carried out. On the basis of their data, a real temperature change in the roller unit of the molding machine is considered, with a comparative analysis of existing ones with a newly designed design.

The change of the energy potential in the interaction of the viscous medium with rotating roller working bodies in the molding machine is considered. An exchange of energy between moving particles is discovered due to collisions of molecules of a more heated part of the body with a greater energy and the transfer of the energy particle to adjacent particles with less energy. It is noted that the definition of temperature fluxes during the process of injection of the medium by roller working bodies plays an important role in calculating the design of molding, roll-over, mixing equipment.

DOI: $10.24263 / 2225-2924-2018-24-6-13$ 


\section{МЕТОДИКА РОЗРАХУНКУ ОПТИМАЛЬНИХ ПАРАМЕТРІВ ВАЛКОВОГО РОЗКАЧУВАННЯ}

\section{І.Я. Стадник, С.І. Федак}

Тернопільський національний технічний університет імені Івана Пулюя Б.С. Пащенко, Н.А. Ткачук Національний університет харчових технологій

У статті проведено аналітичний аналіз дї валків на середовище при деформаційних впливах. Запропоновано шляхи вибору оптимального варіанта прочесу для забезпечення максимального або мінімального значення параметрів (критерію). Розглянуто фізичну сутність рівняння енергетичних потоків інтенсивності деформачії маси середовища, що залежить від способу прикладання механічних сил, ступеня його попередньої дисперсності (рецептура) і фізико-механічних властивостей. Для більшої наглядності і розуміння загального виконання досліджень запропоновано схему причинно-наслідкових зв'язків між середовищем і валком, ше визначають зміну температури проиесу нагнітання тіста.

Відмічено, щуо визначення температурних потоків при проходженні процесу нагнітання середовища валковими робочими органами відіграє важливу роль для розрахунків конструювання формувального, розкочувального, змімувального обладнання. Одержані дані дають відповідь на ряд запитань про можливість терморегулювання прочесу дії робочих органів на середовище.

Розглянуто зміну енергетичного потенціалу при взаємодії в'язкого середовища з обертовими робочими органами ролика у формувальній машині. Обмін енергії між рухомими частинками виявлясться внаслідок зіткнення молекул більш нагрітої частини тіла з більшою енергією та перенесення енергетичної частки до сусідніх частинок з меншою енергією. Відзначено, що визначення температурних потоків під час процесу інжекиії середовища робочими органали роликів відіграє важливу роль у розрахунку дизайну формування, перевертання, змімування.

Ключові слова: тісто, нагнітання, теплопровідність, поширення теплоти, тепловий потік, валок, фаза, середовище.

Постановка проблеми. Одним із основних напрямків раціонального технічного забезпечення процесу формування виробів у різних галузях промисловості $є$ машини з валковими робочими органами. На сьогодні розроблено не так багато конструкцій валкових робочих органів, які виконують технологічну операцію з нагнітання, розкачування, транспортування в'язкого середовища. Багато $з$ цих машин потребує удосконалення та дослідження 3 метою впровадження нових розробок у їх виробництво. Особлива увага приділяється малогабаритним ефективним машинам з контрольованими процесами, що відбуваються в робочій камері. При створенні або модернізації малогабаритних машин з явно вираженими валковими робочими органами особливу увагу необхідно зосередити на обгрунтуванні технологічної схеми та відпо- 
відному конструктивному розв'язанні прийнятих рішень $[1 ; 2]$. Оскільки конструктивні параметри взаємопов'язані з процесом, то це суттєво впливає на можливість виготовлення такої машини в умовах підприємств, технологічні можливості яких орієнтовані на ремонт і відновлення техніки.

Машини, які застосовуються для формування в'язкого середовища, повинні впливати на нього таким чином, щоб втрати сировини і готової продукції були мінімальними, а якість виробів висока. Це вимагає забезпечення повної відповідності режимів обробки, геометричних форм і конструктивних параметрів робочих валкових органів та структурно-механічним властивостям в'язкого середовища. Поставлена проблема визначила сучасні тенденції конструювання валкових робочих органів у машин різного класу, де вони виконують робочі процеси: розкачування, нагнітання, замішування, транспортування [3].

Відставання наукових розробок від потреб практики пояснюється надзвичайно широким діапазоном властивостей технологічних середовищ, різноманіттям використовуваних матеріалів для їх транспортування і відмінністю умов їх експлуатації [1]. Крім того, дослідження розкачування в'язкого середовища валками пов'язане з певною складністю через необхідність залучення до розв'язання проблем сучасних знань і методів з різних галузей науки: фізико-хімічної механіки матеріалів, фізики твердих тіл, металознавства тощо.

Аналіз останніх досліджень і публікацій. Конструктивні параметри валків спрямовані для забезпечення потоків тіста при його вирівнюванні $\mathrm{i}$ перерозподіленні в об'ємі його маси за рахунок плавного затягування, транспотування і нагнітання в зазорі між ними. Хоча процес нагнітання середовища (тіста) за допомогою валків на перший погляд здається простим, однак побудова його математичної моделі і пошук основних розрахунків залежностей досить складний. Зараз є ряд рішень вказаної задачі, які базуються на спрощенні дійсного процесу і не враховують впливу еластично-в'язкої та пластичної структури тіста і дії на неї коливань тиску.

У загальному випадку продуктивність вузла нагнітання (кг/с), що має валкові робочі органи різного діаметра, які обертаються з різною швидкістю, може бути визначена за такою формулою [3]:

$$
\Pi=\pi l \delta \rho\left(R_{1} n_{1} K_{1}+R_{2} n_{2} K_{2}\right) .
$$

Для випадку однакових діаметрів валкових робочих органів, які обертаються з однаковою швидкістю, продуктивність розраховують так:

$$
\Pi=2 \pi R l \delta n \rho K,
$$

де $l$ - довжина робочого ланцюга живильника, м; $\delta$ - ширина зазору, м; $R_{1} \mathrm{i}$ $R_{2}$ - радіуси валків, м; $n_{1}$ і $n_{2}$ - частота їх обертання, $\mathrm{c}^{-1} ; K_{1}, K_{2}$, коефіцієнти подачі тіста, що залежать від діаметра валка і консистенції тіста. Для тіста 3 пшеничного борошна I та вищого гатунків $K$ становить 0,7 при $R=$ $=0,15$ м, при зменшенні $R-$ знижується; $\rho$ - середня густина тіста, кг $/ \mathrm{M}^{3}$.

Через те, що тиск тіста на валкові робочі органи передається по нормалі, на підставі робочого тиску, який задається, і епюри його зміни по довжині 
робочої камери можна визначити сили, які діють на них в зонах живлення i розкачування:

$$
\begin{gathered}
P_{\text {п }}=0,5 P_{\mathrm{p}} R l ; \\
P_{\mathrm{H}}=P_{\mathrm{p}} R l \beta .
\end{gathered}
$$

Момент на валковому робочому органі створюється під дією тангенціальних сил $P_{\text {п }}$ i $P_{\text {н }}$, що виникають внаслідок тертя тіста по валику і направлені в бік, протилежний напрямку обертання валиків.

$$
\begin{gathered}
M_{\text {п }}=0,5 P_{\mathrm{p}} R^{2} \operatorname{ltg} \varphi ; \\
M_{\mathrm{H}}=P_{\mathrm{p}} R^{2} k \operatorname{ltg} \varphi,
\end{gathered}
$$

де $\varphi$ - кут тертя тіста по валковому робочому органі; для тіста пшеничного залежно від рецептури і вологості становить $25-30^{\circ} ; \operatorname{tg} \varphi$ ( змінюється від $0,47$ до 0,57$)$.

Оскільки валкові робочі органи зв'язані між собою зубчастою передачею і обертаються в різні боки, то їх крутні моменти збігаються. В нашому випадку результуючий момент на приводному валу (в Н·м) становить:

$$
M=P_{\mathrm{p}} R^{2} l(\alpha+2 \beta) \operatorname{tg} \varphi .
$$

Для виконання вказаних розрахунків необхідно знайти раціональні конструктивні розміри валків, які відповідають проектній потужності на заданих сортах тіста. У наведених розрахунках відсутні визначення впливу кута затягування (контакту) на розподілення стикованості маси тіста при нагнітанні, тобто в зонах вузла.

Матеріал. Тісто, вологістю $33 \%$, для бубликів із пшеничного борошна вищого сорту на пресованих дріжджах, готувалося безопарним способом 3 тривалістю бродіння 60 хвилин при температурі $32-33^{\circ} \mathrm{C}$. Якість пресованих дріжджів відповідає стандартам. Характеристики борошна пшеничного:

- масова частка вологи, \% - 14,5;

- вміст сирої клейковини, \% - 28;

- опір клейковини стисненню на приладі ІДК-1, од.прил. - 54;

- розтяжність клейковини, см - 14.

Методи. Будь-яку зі структурних схем існуючих і розроблених 3 використанням валкових робочих органів можна математично описати за наявності рівнянь, що зв'язуються у часі безперервними функціями. До них відносяться геометричні розміри обладнання та характеристики робочих валків, а також властивості і фізико-механічний стан в'язкого середовища, що залежить від умов розкачування.

На основі розроблених підходів для опису процесу нагнітання тіста в зазорі між валками [4-6], було використано гідродинамічну теорію каландрування псевдопластичної рідини. Це дає змогу встановити кількісні залежності між геометричними характеристиками робочого простору (зазору) та властивостями матеріалів і режимів обробки. При використанні цієї теорії 
процесу одержано ряд формул, що дають змогу визначити тиск у зазорі між валками, виходячи з параметрів і в'язкості середовища.

Визначені в результаті експерименту залежності описуються частковими алгебраїчними функціями. Для узагальнення часткових залежностей використано багатофакторну функцію Протодияконова, застосування якої для обробки результатів хімічних досліджень [2; 6] дає змогу отримати адекватні результати.

Характеристики тіста 3 незруйнованою структурою досліджували приладом PB-8. Досліди проводилися при невеликих зусиллях зсуву, величина яких менша за граничне напруження зсуву, фіксуючи через кожні 10-20 секунд величини деформацій, які визначають за відхиленням стрілки. Знаючи геометричні характеристики приладу і дані вимірювання, розраховано напруження зсуву $\tau^{\prime}$ :

$$
\tau^{\prime}=\tau-\tau_{\mathrm{\kappa}}=\frac{\left(m-m_{0}\right) g R_{\text {шк }}}{2 \pi R_{\mathrm{B}}^{2} h_{\text {пр }}},
$$

де $m$ - маса вантажу, який обертає ротор. Складається 3 маси двох важків i маси чашок, кг (за винятком величини, що компенсує тертя в підшипниках); $m_{0}$ - маса вантажу, при якій ротор починає обертатися. Відповідно до [4] визначали пластичну в' язкість: $\mu_{\text {пл }}=\left(\tau-\tau^{1}\right) / \gamma$.

Аналіз досліджень нагнітання тіста та показників роботи існуючих машин свідчить про складність процесу, недостатню стабільність і надійність роботи, компоненти подаються в робочу камеру нерівномірно. Крім того, на якість нагнітання валками впливає цілий ряд інших факторів: фізикомеханічні властивості сировини, режим роботи, недостатній імпульс зовнішніх сил в осьовому зміщенні та надмірна кількість робочих органів тощо. Це пов'язано з тим, що конструкція, параметри робочих органів і кінематика руху їх ще недостатньо вивчені. Тому, незважаючи на значну кількість наукових напрацювань, актуальною проблемою залишається розробка нових, більш перспективних технічних конструктивних рішень робочих органів, робочих камер з покращенням якісних показників виробів на основі побудови математичної моделі.

У [7] з'ясовано, що при стисканні тісто в закритому об'ємі виявляє властивості пружності за рахунок в основному газової фази та частково пружного білкового скелета. Визначення впливу стискання тіста у процесі розкачування обгрунтовує подальші технологічні процеси й дослідження його властивостей. Стискуваність дріжджового тіста [7] пояснюється двома причинами: стискуваністю газових бульбашок і деформацією структурної сітки. За умов розкачування говорити про зменшення відстаней між молекулами біополімерів у складі тіста недоцільно, оскільки для цього потрібен надто високий тиск. Відповідно, важаємо, що об'єм напівфабриката зменшується тільки внаслідок стискання і подальшого розчинення у рідкій фазі тіста газових пухирців.

Як бачимо, визначення руху середовища в зазорі між валками є досить складною і в той же час практично важливою проблемою. Вона пов'язана 3 
необхідністю проведення різного роду розрахунків формуючих робочих валків у визначенні їх дії на середовище. Для вирішення такого класу задач необхідно залучити алгебру логіки і теорію множини, властивості середовища, що дають змогу розглянути компонування як упорядковану множину робочих ланок, а різноманітні їх сполучення — як логічні відношення елементів цієї множини. Вирішення поставлених завдань можливе на основі ретельного вивчення суті процесу, що відбувається під час розкачування. Такий підхід дасть змогу встановити характер стадійного розподілення стикованості маси тіста в зазорі між обертовими валками з урахуванням кута контакту.

Мета дослідження: розроблення методики визначення і розподілення рівня стискання тіста в зазорі між валковими робочими органами.

Викладення основних результатів дослідження. Вивчення праць $[1 ; 4$; 5] показало, що нерівномірність швидкості руху середовища (бубличного, дріжджового, пшеничного тіста) обумовлена характером їхньої течії. Тому суттєвим фактором збільшення ефективності інтенсивної дії валків на середовище $\epsilon$ рівномірність розкачування його елементарних об'ємів, що надходять із робочої камери машини. Оскільки питома подача середовища $\epsilon$ однаковою для всіх елементарних об'ємів маси, що знаходяться в зазорі між валками, в 'язкість залишається постійною і ми враховували ії при розрахунках.

Розглянемо процес розкачування тіста між валками. Закономірність зміни товщини пласту тіста при розкачуванні між валками наведено на рис. 1. При розкачуванні валками циліндричної форми товщина тіста постійно змінюється в середній частині пласта, тобто в зоні захвачування. На виході з валків товщина одинакова. Всі цикли розкачування валками криволінійної поверхні вібуваються без зміни зазора середньої части валків від захвата до захвату. Це дає змогу стисненню і здвигу тіста при формуванні валками по ходу розкатки 3 досягненням по всій поверхні пласта одинакової товщини. Валки одного і того ж діаметра обертаються з однаковою кутовою швидкістю $\omega$, радіусом $R$, довжиною $L$. Робоча поверхня валків знаходиться між зазорами $h_{s}$ i $h_{0}$, де $h_{s}$, відстань між поверхнями валків при наявності тіста; $h_{0}-$ мінімальний зазор між валками.

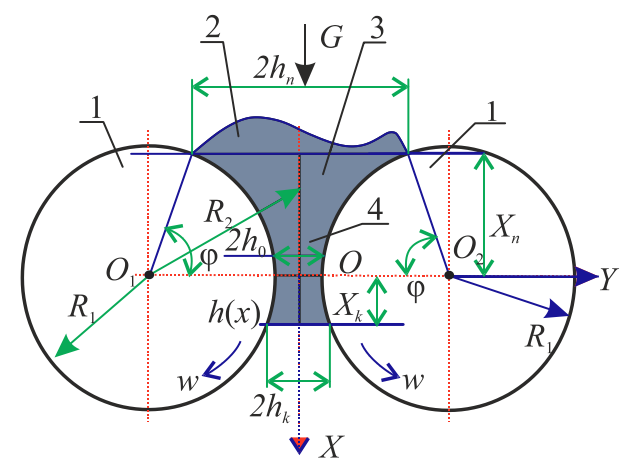

Рис. 1. Схема руху тіста у вертикальному зазорі між валками:

1 - валки; 2 - тісто; 3, 4 - перша (протитокова)

і друга (прямотокова) зони в'язкопластичної зсувної течії 
При нагнітанні маса тіста багаторазово проходить через усі ділянки робочої камери, при цьому отримує деформації. Зусилля на тісто характеризуються збільшенням тиску в напрямку обертання валків і асиметрією діючих сил, які визначають геометрію робочого об’єму (рис. 1). Маса тіста при виході з ділянки розкачування деформується розтягуванням одночасно з об'ємним зсувом. Найбільш суттєвою $є$ складова тиску, що виникає внаслідок допустимих напружень i зміни фізико-механічних властивостей тіста. 3 урахуванням конструктивних особливостей вузла нагнітання математична модель процесу виглядає так (6):

$$
P=\frac{2 \mu}{R} \int \frac{\left(Q-\frac{\omega R h}{2}\right) d \varphi}{(R+h)\left[\lg \left(1+\frac{h}{R}\right)-\frac{h}{2}\left(\frac{1}{R}+\frac{1}{R+h}\right)\right]}+C_{3}
$$

де $R$ - радіус валкового робочого органу, мм; $h$ - величина зазору, мм; $Q-$ витрати тіста, кг/с; $\mu$ - вязкість Па·с.

Нехай $P(\varphi=0)=P_{0}$, тоді:

$$
\begin{gathered}
P=\frac{2 \mu}{R} \int \mid+C \Rightarrow+C_{3}=P_{0}-\frac{2 \mu}{R} \int ; \\
P_{0}=\left.\frac{2 \mu}{R} \int\right|_{\varphi=0}+C_{3} \Rightarrow C_{3}=P_{0}-\left.\frac{2 \mu}{R} \int\right|_{\varphi=0} \\
P(\phi)=P_{0} \frac{2 \mu}{R} \int_{0}^{\varphi} \frac{\left(Q-\frac{\omega R h}{2}\right) d \varphi}{(R+h)\left[\ln \left(1+\frac{h}{R}\right)-\frac{h}{2}\left(\frac{1}{R}+\frac{1}{R+h}\right)\right]} .
\end{gathered}
$$

Введемо позначення :

$$
\begin{gathered}
I_{k}(\varphi)=\int_{0}^{\varphi} \frac{h^{k} d \varphi}{(R+h)\left[\ln \left(1+\frac{h}{R}\right)-\frac{h}{2}\left(\frac{1}{R}+\frac{1}{R+h}\right)\right]} ; k=0,1 \\
I_{1}(\varphi)=\int_{0}^{\varphi} \frac{h^{k} d \varphi}{(R+h)\left[\ln \left(1+\frac{h}{R}\right)-\frac{h}{2}\left(\frac{1}{R}+\frac{1}{R+h}\right)\right]} .
\end{gathered}
$$

Тоді:

$$
P(\varphi)=P_{0}+\frac{2 \mu}{R}\left(Q I_{0}(\varphi)-\frac{\omega R}{2} I_{1}(\varphi)\right) .
$$

Вилучимо змінну $Q$ з умов, що розподіл тиску є періодичною функцією кута $\varphi$, тобто: $P(\varphi+2 \pi)=P(\varphi)$. 
Для випадку $\varphi\left(\frac{\pi}{2}\right)=P(0)=P_{0}$, отже:

$$
P=P_{0}+\frac{2 \mu}{R}\left[\left(Q I_{0}\left(\frac{\pi}{2}\right)-\frac{\omega R}{2} I_{1}\left(\frac{\pi}{2}\right)\right)\right] .
$$

3 рівняння видно, що величина розміщення маси тіста (кут поверхні затягування маси на валку) значною мірою визначає величину тиску. Функція $P(\varphi)$ залежить від кута, а не від часу, тому похідні не будуть характеристиками швидкості та прискоренням процесу ущільнення. Вводимо додаткові функції, що розкривають дискретність процесу нагнітання:

$$
\begin{gathered}
F(\varphi)=\ln \left(1+\frac{h}{R_{2} \cdot \sin (\varphi)}\right)-\frac{h}{2} \cdot\left(\frac{1}{R_{2} \cdot \sin (\varphi)}+\frac{1}{R_{2}}\right) ; \\
L(\varphi)=Q-\omega \cdot R_{2} \cdot \sin (\varphi) \cdot \frac{h}{2} .
\end{gathered}
$$

Враховуючи наші дані та використавши (8), побудовано графік (рис. 2).

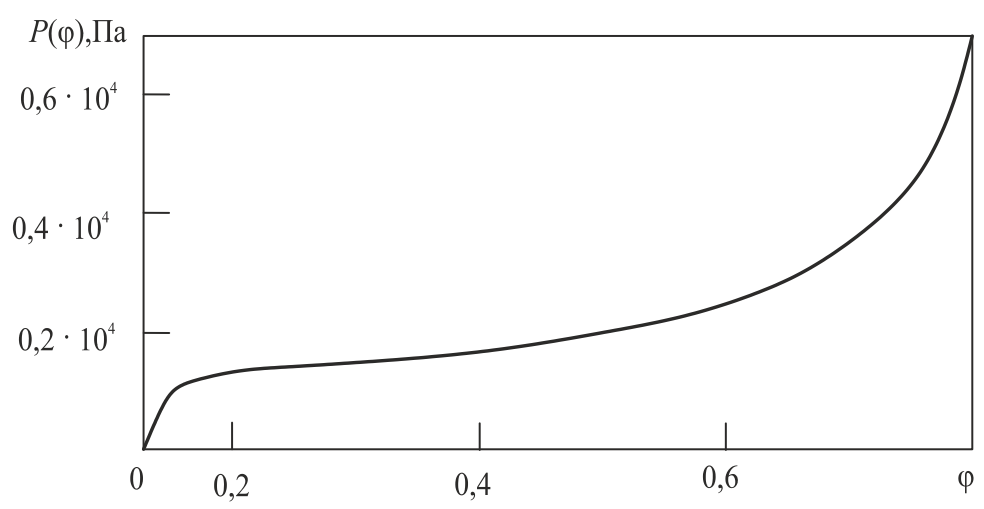

Рис. 2. Графік залежності тиску від кута затягування $\varphi$

Як бачимо, функція $P(\varphi)$ визначена для кута $\varphi$ від 0,1277 до 0,8034 рад. Вона характеризується трьома ділянками залежно від кута $\varphi$ (рис. 2). Перша ділянка (початок процесу) $\varphi$ від 0,8034 до 0,65 радіан (процес затягування й ущільнення). Він характеризується зменшенням $P(\varphi)$ від $0,705 \cdot 10^{4}$ до $0,229 \cdot 10^{4}$. При цьому відбувається нелінійне зменшення похідної $\frac{d P(\varphi)}{d \varphi}$ та нелінійне зменшення другої похідної $\frac{d^{2} P(\varphi)}{d \varphi^{2}}$ до 0. Друга ділянка вказує на стабілізацію процесу, де $\varphi$ знаходиться від 0,65 до 0,24 радіан. Вона також характеризує часткове зменшення $P$ від $0,229 \cdot 10^{4}$ до $0,145 \cdot 10^{4}$. Відповідно, відбувається лінійне зменшення похідної $\frac{d P(\varphi)}{d \varphi}$ та другої похідної $\frac{d^{2} P(\varphi)}{d \varphi^{2}}=0$ (або невиз- 
начена). Третя ділянка при $\varphi$ від 0,24 до 0,1277 радіан: функція $P(\varphi)$ зменшується від $0,145 \cdot 10^{4}$ до 0 ; нелінійне збільшення похідної $\frac{d P(\varphi)}{d \varphi}$; нелінійне зменшення другої похідної $\frac{d^{2} P(\varphi)}{d \varphi^{2}}$ від 0 .

3 вищенаведеного обгрунтовання впливу взаємодії валка 3 тістом випливає, що оптимальна пружність тіста істотно залежить від співвідношення заданих величин утвореного стискання між ними та незначно - від температури навколишнього середовища в діапазоні температур $t_{0}$ від $20^{\circ} \mathrm{C}$ до $35^{\circ} \mathrm{C}$. 3 огляду на те, що проходить зміна стискання тіста з відхиленням і, відповідно, структурно-механічних властивостей тіста, використовуючи математичну модель (8), ми визначили вплив оптимального рівня стискання тіста на структуру готової продукції. При цьому використано дослідні дані зміни величин в'язкості відносно плину кута затягування маси тіста. Встановлено, що ця величина коливається в малих діапазонах і для в'язкості тіста на початку дискретної дії валків має незначні зміни. Конструкція поверхні нового валка дала змогу при однакових технологічних параметрах зменшити вплив на тісто і покращити якість формування. При цьому зменшуються втрати сухих речовин, технологічний брак. Графічна залежність оптимального ступеня стискання тіста від співвідношення заданих величин зміни в'язкості з плином кута затягування побудована на рис. 3. Одночасно відображено зміна структури готових бубликів 3 урахуванням дискретності процесу нагнітання за розробленою методикою [7].

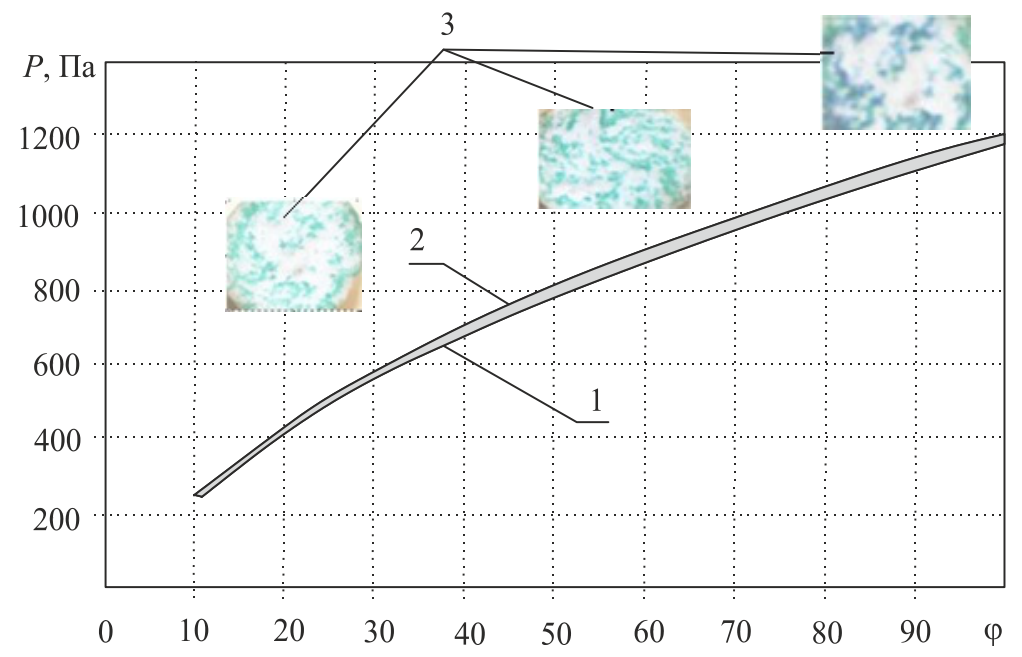

Рис. 3. Вплив кута затягування тіста $\varphi$ на його стискання $P$ при нагнітанні на другій ділянці: 1 - стискання після багатьох циклів дискретності; 2 - стискання на початку дії валків; 3 - структура готового бублика

3 графічної залежності (рис. 3) випливає, що стискування маси тіста відбувається при змінному тиску. Ця величина коливається в малих значеннях і 
для в'язкості тіста на початку дискретної дії валків є незначними. Це наочно видно із структури бублика. Конструкція поверхні нового валка дала змогу при однакових технологічних параметрах зменшити вплив на тісто і покращити якість формування. При цьому зменшуються втрати сухих речовин i технологічний брак.

\section{Висновки}

Розроблена модель дає змогу визначати стискуваність тіста на початкових i кінцевих значеннях в'язкості при додержанні заданих технологічних і конструктивних параметрах (температура, рецептура, форма поверхні валка).

Наведений аналіз може стати основою для розробки інженерної методики проектування робочих органів для регулювання стабільності процесу.

\section{Лiтература}

1. Drozdziel Pawel, Derkach Andrij, Stadnyk Igor, Vitenko Tatiana Simulation of components mixing in order to determine rational parameters of working bodies. Advances in Science and Technology Research Journal. 2016. Vol. 9. P. 130-138.

2. Stadnyk I., Novak L., Matenchuk L. Global rheological approach to the quality of medium injected by the rollers. Potravinarstvo Slovak Journal for Food Sciences. 2018. Vol. 1. P. 1-8.

3. Гаврилко П., Деркач А., Стадник І. Обгрунтування параметрів, що відбуваються в робочих камерах машин з валковими робочими органами. Хранение и переработка зерна. 2017. Том 2, № 2(210). С. $34-38$.

4. Арет В.А., Мачихин Ю.А. Формование конфетных масс выдавливанием. Москва: МТИПП, 1969. $35 \mathrm{c}$.

5. Андреев А.Н. Выбор реологической модели пресного слоеного теста. Проблемы оборудования в торговле и общественном питании: Внутривуз. сб. научн. тр. Л.: ЛИСТ, 1976. Вып. 58. С. $5-8$.

6. Зайцев А.В., Пеленко Ф.В. Моделирование течения вязкой жидкости в трубе. Электронный научный журнал «Прочессы и аппараты пищевых производств». Санкт-Петербург: СПбГУНиПТ, 2012. № 1. март 2012.

7. Стадник І.Я. Науково-технічні основи процесів та розробка обладнання для безлопатевого замішування тіста: автореферат док.тех.наук. Київ. 2013. 42 c.

8. Андреев А.Н. Расчет энергосиловых параметров процесса раскатки теста на валковой машине. Вопросы торгово-технологического оборудования: Внутривуз. Сб. науч. тр. Л.: ЛИСТ, 1975. Вып. 50. С. 4-7. 